\title{
Acute myocardial infarction is associated with endothelial glycocalyx and cell damage and a parallel increase in circulating catecholamines
}

\author{
Sisse R Ostrowski ${ }^{1 *}$, Sune H Pedersen², Jan S Jensen ${ }^{2,3}$, Rasmus Mogelvang ${ }^{4}$ and Pär I Johansson ${ }^{1,5}$
}

\begin{abstract}
Introduction: Excessive sympathoadrenal activation in critical illness contributes directly to organ damage, and high concentrations of catecholamines damage the vascular endothelium. This study investigated associations between potential drivers of sympathoadrenal activation, circulating catecholamines and biomarkers of endothelial damage and outcome in ST segment elevation myocardial infarction (STEMI)-patients, hypothesizing that the catecholamine surge would reflect shock degree and correlate with biomarkers of endothelial damage.

Methods: This was a prospective study of 678 consecutive STEMI-patients admitted to a single high-volume invasive heart centre for primary percutaneous coronary intervention (pPCl) from September 2006 to July 2008. Blood samples were drawn immediately before pPCl. Plasma adrenaline, noradrenaline, syndecan-1 and thrombomodulin were measured retrospectively with complete data in 571 patients (84\%). Median follow-up time was 28 (IQR 23 to 34) months. Follow-up was $99.7 \%$ complete. Outcomes were all-cause and cardiovascular mortality, re-myocardial infarction and admission due to heart failure.
\end{abstract}

Results: Circulating noradrenaline and adrenaline correlated weakly but independently with syndecan- 1 (rho $=0.15$ and rho $=0.13$, both $P<0.01$ ) and thrombomodulin (rho $=0.11$ and rho $=0.17$, both $P<0.01$ ), biomarkers of glycocalyx and endothelial cell damage, respectively. Considering biomarkers, patients with shock pre-pPCI had higher adrenaline and syndecan-1 and patients admitted to ICU post-pPCI had higher syndecan-1 (all $P<0.05$ ), and in the patients with shock $(n=51)$ catecholamines correlated strongly with thrombomodulin and syndecan-1 (rho $=0.31$ to 0.42 , all $P<0.05$ ). During follow-up, 78 (14\%) patients died (37 cardiovascular deaths) and 65 (11\%) were admitted with heart failure. By multivariate Cox proportional hazards analyses, one quartile higher plasma adrenaline was weakly but independently associated with both 30-day and long term mortality and heart failure (30-day all-cause mortality hazard ratio $(95 \% \mathrm{Cl}) 1.39$ (1.01 to 1.92$), P=0.046 ; 30$-day heart failure 1.65 (1.17 to 2.34), $P=0.005$; and long-term cardiovascular mortality 1.49 (1.08 to 2.04), $P=0.014$ ). Furthermore, one quartile higher syndecan-1 was also weakly but independently associated with long-term all cause mortality (1.26 (1.02 to 1.57), $P$ $=0.034$ ).

Conclusions: In STEMI patients treated with $\mathrm{PPCl}$, catecholamines correlated weakly with biomarkers of endothelial damage, with the strongest correlations and highest adrenaline and syndecan-1 levels in patients with shock. Furthermore, adrenaline and syndecan-1 were weakly but independently associated with mortality and heart failure. Acute myocardial infarction appears to cause significant endothelial cell and glycocalyx injury and a parallel increase in circulating catecholamines.

\footnotetext{
* Correspondence: sisse.ostrowski@gmail.com

'Section for Transfusion Medicine at Capital Region Blood Bank,

Rigshospitalet, Blegdamsvej 9, Copenhagen, DK-2100, Denmark

Full list of author information is available at the end of the article
} 


\section{Introduction}

Excessive sympathoadrenal activation is a hallmark of acute critical illness and the accompanying increase in circulating catecholamines induces widespread dosedependent effects on metabolism and the vascular system [1-3]. This 'fight-or-flight' response may, however, become maladaptive and contribute to organ damage [2-4], and in high concentrations, catecholamines directly damage the vascular endothelium resulting in local edema, endothelial cell swelling, necrosis and progressive de-endothelialization [5,6]. In two independent cohorts of trauma patients, we recently reported that plasma adrenaline correlated strongly with circulating biomarkers of endothelial activation and damage $[7,8]$ and that the plasma adrenaline level was independently associated with circulating syndecan-1 [9], a recognized biomarker of endothelial glycocalyx degradation [10]. Furthermore, non-surviving trauma patients had increased levels of adrenaline and syndecan-1 and both predicted 30-day mortality $[7,9]$.

Acute myocardial ischemia and infarction (MI) immediately activates the sympathoadrenal system resulting in excessive increases in circulating levels of adrenaline and noradrenaline $[11,12]$, the latter through direct release from the infarcted myocardium [12]. Apparently, catecholamines induce opposite directed effects on the endothelium (progressive activation and damage) [4-6] and circulating blood (initial hypercoagulability followed by progressive hypocoagulability and hyperfibrinolysis) [4,13-18], and we infer that this reflects an evolutionary adapted response aimed at maintaining blood flow through a damaged and procoagulant microvasculature in the (shocked) critically ill patient [4]. In accordance with this notion, patients with cardiac arrest present with hyperfibrinolysis on-scene (extreme hypocoagulability as a result of excessive endothelial release of profibrinolytic factors) [19] and increased circulating levels of endothelial derived biomarkers (syndecan-1, thrombomodulin, sICAM-1, sVCAM-1, sE-selectin) in the hours after cardiopulmonary resuscitation [20,21]. Although acute critical illness, with shock/hypotension, ischemia and reperfusion, massive tissue injury and systemic infection/inflammation, activates and potentially damages the endothelium $[8,9,20-27]$, the relative contribution of the concurrent neurohumoral, including sympathoadrenal, activation to the endothelial injury and ensuing (multiple) organ failure [2-4] is not known.

MI patients have varying degrees of hypotension/ shock and increases in circulating catecholamines, in the absence of massive tissue injury. Given this, the aim of the present study was to investigate associations I) between potential drivers of sympathoadrenal activation and/or endothelial damage and II) between circulating levels of catecholamines and biomarkers of endothelial glycocalyx (syndecan-1 [10]) and cell (soluble thrombomodulin, sTM [28-30]) damage and organ failure/ outcome, in patients with ST elevation MI (STEMI). We hypothesized that shock and high catecholamine levels would be associated with evidence of enhanced damage to the glycocalyx and endothelium and that high levels of both catecholamines and endothelial derived biomarkers would be associated with a poor outcome.

Here, we report that circulating adrenaline and noradrenaline levels in STEMI patients treated with percutaneous primary coronary intervention (pPCI) correlated weakly with syndecan-1 and sTM, biomarkers of glycocalyx and endothelial cell damage, respectively, with the strongest correlations and highest levels of adrenaline and syndecan-1 in patients with shock prior to pPCI. Furthermore, adrenaline was independently associated with short-and long-term mortality and heart failure (HF), and syndecan-1 was independently associated with long-term mortality. These findings indicate that acute MI causes significant endothelial glycocalyx and cell injury and a parallel increase in circulating catecholamines and they support the notion that a dose-dependent association exists between disease severity, sympathoadrenal activation and endothelial damage.

\section{Materials and methods}

\section{Study population}

A total of 730 patients were treated with pPCI for STEMI at Gentofte University Hospital from September 2006 to September 2008 [31]. Plasma was retrospectively analyzed for adrenaline, noradrenaline, syndecan- 1 and sTM in $678,677,628$ and 574 patients, respectively, with complete measurements of all 4 biomarkers in 571 patients, that is, the present study cohort. If patients had more than one pPCI-procedure within this period, the first procedure was defined as the index-procedure.

Inclusion criteria and STEMI definition are as follows: chest pain $>30$ minutes and $<12$ hours and cumulative persistent ST-segment elevation $\geq 4 \mathrm{~mm}$ in at least two contiguous precordial ECG-leads or $\geq 2 \mathrm{~mm}$ in at least two contiguous limb ECG-leads. A significant increase in troponin I ( $\mathrm{TnI},>0.5 \mu \mathrm{g} / \mathrm{l}$ ) was required for inclusion in the present study. The study was approved by the local scientific ethical committee and The Danish Data Protection Agency, and complied with the Second Declaration of Helsinki. Written informed consent was obtained from all patients.

\section{Baseline-and procedural data}

Prospectively collected data (baseline, disease severity) are as follows: hypertension, hypercholesterolemia and diabetes (patients taking blood-pressure-, cholesterol-or 
glucose-lowering drugs, respectively, on admission and for the latter, with fasting plasma glucose concentration $\geq 7 \mathrm{mmol} / \mathrm{L}$ or non-fasting plasma glucose concentration $\geq 11.1 \mathrm{mmol} / \mathrm{L}$ ); previous diagnosis of MI; multivessel disease (two-or three vessel-disease); complex lesions (type C-lesions); stenosis degree ( 1 or $>1$ infarcted segments); number of lesions (1 to 5); presence of shock prior to pPCI (systolic blood pressure $\leq 90 \mathrm{mmHg}$, need for vasopressor therapy and/or cardiopulmonary resuscitation pre-hospital or at admission) and admission to the ICU prior to hospital discharge.

TnI-levels were measured at admission and six hours and twelve hours after admission; the peak TnI level was used in the statistical analyses. C-reactive protein (CRP), estimated glomerular filtration tate (eGFR) and standard hematology analyses (hemoglobin, platelet, leukocyte and neutrophil counts) were measured at admission.

The $\mathrm{pPCI}$ procedure was performed according to contemporary interventional guidelines using pre-treatment with unfractionated heparin, acetyl salicylic acid and clopidogrel. Subsequent medical treatment included antiischemic, lipid-lowering and anti-thrombotic drugs according to current treatment guidelines.

\section{Follow-up and study end points}

Follow-up was $99.7 \%$ complete (two patients were lost to follow-up due to emigration). The study endpoints were all-cause mortality, cardiovascular (CV) mortality, re-MI and admission with clinical signs of HF (dyspnea, fatigue, edema/stasis) combined with a discharge-diagnosis of HF. Follow-up data on mortality were collected from the National Person Identification Registry which holds information on vital status. Follow-up data on re-MI and admission with HF were collected using hospital source data as well as data from the Danish National Board of Health's National Patient Registry, using International Classifications of Diseases, tenth revision (ICD-10) codes. Median follow-up time was 28 months (IQR 23 to 34).

\section{Blood sampling}

Peripheral arterial blood was drawn from the femoral sheath at the beginning of the procedure. Blood was allocated to different containers including $4 \mathrm{ml}$ ethylenediaminetetraacetic acid (EDTA) tubes and was centrifuged at 10,000 RPM for 10 minutes within 30 minutes of collection. Plasma was stored in NuncCryo tubes (Nunc, Roskilde, Denmark) at $-80^{\circ} \mathrm{C}$.

\section{Enzyme linked immunosorbent assay (ELISA) measurements}

Biomarkers of sympathoadrenal activation (adrenaline, noradrenaline) and endothelial glycocalyx (syndecan-1) and endothelial cell damage (sTM) were measured by commercially available immunoassays in EDTA plasma according to the manufactures' recommendations: for adrenaline and noradrenaline (2-CAT ELISA ${ }^{\text {FAST TRACK, }}$ Labor Diagnostica Nord GmbH \& Co. KG, Nordhorn, Germany; lower limit of detection (LLD) $10 \mathrm{pg} / \mathrm{ml}$ (adrenaline) and $50 \mathrm{pg} / \mathrm{ml}$ (noradrenaline), respectively; for syndecan-1 (Diaclone SAS, Besancon, France; LLD $4.94 \mathrm{ng} / \mathrm{ml}$ ); and for sTM (Nordic Biosite, Copenhagen, Denmark; LLD $0.38 \mathrm{ng} / \mathrm{ml}$ ). Values below LLD were recorded as the LLD value $(n=62,78,8$ and 4 for adrenaline, noradrenaline, syndecan-1 and sTM, respectively).

\section{Statistics}

Statistical analysis was performed using SAS 9.1 (SAS Institute Inc., Cary, NC, US). Data from patients stratified according to adrenaline or syndecan-1 quartiles were compared by Kruskal-Wallis and Chi-square/ Fisher's exact tests, as appropriate, and by Bonferroni corrected Wilcoxon Rank Sum and Chi-square/Fischer exact post-hoc tests. Biomarker levels in patients stratified according to shock prior to pPCI or ICU admission before discharge were compared by Wilcoxon Rank Sum tests. Correlations between biomarkers were investigated by Spearman's correlations. The contribution of baseline variables to the variation in syndecan-1 and sTM levels was investigated by univariate and multivariate linear regression analyses. The predictive value of quartiles of adrenaline, noradrenaline, syndecan- 1 and sTM for 30-day and long-term all-cause mortality, CV mortality, re-MI and HF were investigated by univariate and multivariate Cox proportional hazards analyses. To maintain robust models, only one variable per five events was allowed in the multivariable Cox analyses of each endpoint. Variables with the lowest $P$-value in univariate Cox analysis were included until the maximum allowed number of variables was reached. Data are presented as medians with inter IQRs. P-values $<0.05$ were considered significant.

\section{Results}

\section{Study patients}

Baseline characteristics and outcome in all patients and in patients stratified according to adrenaline quartiles are presented in Table 1 . With increasing adrenaline quartile, the noradrenaline level increased progressively and more patients presented with shock prior to pPCI, developed HF or died during follow-up. Patients in the highest adrenaline quartiles tended to have lower eGFR and more complex lesions (Type C).

When comparing biomarker levels in patients stratified according to shock prior to pPCI or ICU admission before discharge, adrenaline levels were higher in patients with shock (Figure 1A) and syndecan-1 levels were higher in patients with shock or ICU admission before discharge (Figure 1B,E). sTM tended to be higher 
Table 1 Demography, baseline data and outcome in 571 consecutive STEMI patients treated with primary PCI

\begin{tabular}{|c|c|c|c|c|c|c|c|}
\hline & & All patients & Adrenaline Q1 & Adrenaline Q2 & Adrenaline Q3 & Adrenaline Q4 & $P$-value \\
\hline & & Number $=571$ & Number $=143$ & Number $=143$ & Number $=142$ & Number $=143$ & \\
\hline \multicolumn{8}{|c|}{ Demography and cardiovascular risk factors } \\
\hline Age & years & $63(55-72)$ & $64(54-74)$ & $64(55-73)$ & $62(56-70)$ & $64(57-71)$ & NS \\
\hline Male gender & n (\%) & $419(73 \%)$ & $103(72 \%)$ & $97(68 \%)$ & $112(79 \%)$ & 107 (75\%) & 0.192 \\
\hline Hypertension & n (\%) & $197(35 \%)$ & $51(36 \%)$ & $49(34 \%)$ & $51(36 \%)$ & $46(32 \%)$ & NS \\
\hline Diabetes & n (\%) & $55(10 \%)$ & $17(12 \%)$ & $13(9 \%)$ & $14(10 \%)$ & $11(8 \%)$ & NS \\
\hline Current smoker & n (\%) & $285(50 \%)$ & $70(49 \%)$ & $77(54 \%)$ & $70(49 \%)$ & $68(48 \%)$ & NS \\
\hline Previous Ml & n (\%) & $33(6 \%)$ & $10(7 \%)$ & $8(6 \%)$ & $6(6 \%)$ & $4(4 \%)$ & NS \\
\hline BMI & $\mathrm{kg} / \mathrm{m}^{2}$ & $26(24-29)$ & $26(23-30)$ & $26(23-28)$ & $26(24-30)$ & $26(24-29)$ & NS \\
\hline \multicolumn{8}{|l|}{ Pre-and in-hospital symptoms } \\
\hline Symptom-to-balloon time & $\min$ & $200(134-330)$ & $195(137-325)$ & $225(133-375)$ & $205(131-360)$ & $180(120-299)$ & 0.172 \\
\hline Door-to-balloon time & $\min$ & $60(31-110)$ & $50(30-101)$ & $70(32-120)$ & $63(36-110)$ & $60(31-103)$ & NS \\
\hline \multicolumn{8}{|l|}{ Clinical presentation } \\
\hline Shock prior to $\mathrm{pPCl}$ & n (\%) & $51(11 \%)$ & $7(6 \%)$ & $9(8 \%)$ & $13(12 \%)$ & $22(18 \%)$ & $0.016^{\mathrm{a}}$ \\
\hline Systolic BP & $\mathrm{mmHg}$ & $135(115-150)$ & $131(115-150)$ & $135(116-150)$ & $138(119-150)$ & $130(110-150)$ & NS \\
\hline Diastolic BP & $\mathrm{mmHg}$ & $80(70-90)$ & $80(70-90)$ & $80(70-90)$ & $80(70-90)$ & $80(70-90)$ & NS \\
\hline Left ventricular ejection fraction & $\%$ & $40(30-50)$ & $40(30-50)$ & $40(30-50)$ & $40(30-50)$ & $35(25-45)$ & NS \\
\hline eGFR at admission & $\mathrm{ml} / \mathrm{min}$ & $73(60-88)$ & $76(64-89)$ & $74(56-88)$ & $74(62-88)$ & $70(54-85)$ & 0.052 \\
\hline \multicolumn{8}{|c|}{ Hematology and biomarkers of myocardial necrosis and inflammation } \\
\hline Hemoglobin & $\mathrm{mmol} / \mathrm{L}$ & $8.7(8.1-9.3)$ & $8.7(8.1-9.2)$ & $8.8(8.2-9.3)$ & $8.7(8.1-9.3)$ & $8.7(8.2-9.2)$ & NS \\
\hline Platelet count & $\times 10^{9} / \mathrm{L}$ & $282(234-333)$ & $280(242-346)$ & $292(241-345)$ & $284(233-317)$ & $271(227-332)$ & NS \\
\hline Leukocyte count & $\times 10^{9} / \mathrm{L}$ & $12.2(9.8-15.1)$ & $11.6(9.3-14.5)$ & $12.3(10.1-15.3)$ & $12.5(10.4-14.9)$ & $12.4(9.9-15.5)$ & NS \\
\hline Neutrophil count & $\times 10^{9} / \mathrm{L}$ & $9.2(6.8-11.8)$ & $8.8(6.7-11.3)$ & $8.9(7.2-11.6)$ & $9.5(7.2-12.2)$ & $9.3(6.3-12.2)$ & NS \\
\hline Peak Troponin I & $\mu g / L$ & $90(28-244)$ & $98(24-242)$ & $116(33-261)$ & $60(21-213)$ & $95(38-255)$ & NS \\
\hline CRP & $\mathrm{mg} / \mathrm{L}$ & $3(1-9)$ & $4(1-11)$ & $3(2-9)$ & $3(1-7)$ & $3(2-10)$ & NS \\
\hline \multicolumn{8}{|c|}{ Sympathoadrenal activation and endothelial damage } \\
\hline Adrenaline & $\mathrm{pg} / \mathrm{ml}$ & $59(25-145)$ & $13(10-20)$ & $37(29-50)$ & $83(73-94)$ & $283(213-501)$ & $<0.0001^{\text {abcdef }}$ \\
\hline Noradrenaline & $\mathrm{pg} / \mathrm{ml}$ & $191(90-454)$ & $117(57-236)$ & $150(78-294)$ & $214(108-498)$ & $441(229-1,180)$ & $<0.0001^{\text {abdef }}$ \\
\hline Syndecan-1 & $\mathrm{ng} / \mathrm{ml}$ & $92(52-165)$ & $84(46-156)$ & $81(47-162)$ & 95 (55-168) & $101(52-169)$ & NS \\
\hline Soluble thrombomodulin & $\mathrm{ng} / \mathrm{ml}$ & $2.2(1.6-3.1)$ & $2.1(1.6-3.1)$ & $2.3(1.7-3.2)$ & $2(1.5-2.8)$ & $2.2(1.7-3.2)$ & 0.040 \\
\hline \multicolumn{8}{|l|}{ Infarction type } \\
\hline \multirow[t]{3}{*}{ Lesion type } & A & $83(15 \%)$ & $18(13 \%)$ & $23(16 \%)$ & $27(19 \%)$ & $15(10 \%)$ & 0.194 \\
\hline & B & $209(37 \%)$ & $52(36 \%)$ & $56(39 \%)$ & $54(38 \%)$ & $47(33 \%)$ & \\
\hline & C & $278(49 \%)$ & $73(51 \%)$ & $63(44 \%)$ & $61(43 \%)$ & $81(57 \%)$ & \\
\hline \multirow[t]{5}{*}{ Infarct related artery } & $L A D$ & $262(46 \%)$ & $62(43 \%)$ & $66(46 \%)$ & $60(42 \%)$ & $74(52 \%)$ & 0.092 \\
\hline & $\mathrm{RCA}$ & $246(43 \%)$ & $62(43 \%)$ & $54(38 \%)$ & $69(49 \%)$ & $61(43 \%)$ & \\
\hline & $C x$ & $58(10 \%)$ & $19(13 \%)$ & $20(14 \%)$ & $13(9 \%)$ & $6(4 \%)$ & \\
\hline & LM & $31 \%)$ & $0(0 \%)$ & $1(1 \%)$ & $0(0 \%)$ & $2(1 \%)$ & \\
\hline & Graft & $1(0 \%)$ & $0(0 \%)$ & $0(0 \%)$ & $0(0 \%)$ & $1(1 \%)$ & \\
\hline Complex lesion & n (\%) & $278(49 \%)$ & $73(51 \%)$ & $63(44 \%)$ & $61(43 \%)$ & $81(57 \%)$ & 0.071 \\
\hline Multivessel disease & n (\%) & $160(28 \%)$ & $47(33 \%)$ & $35(24 \%)$ & $37(26 \%)$ & $41(29 \%)$ & NS \\
\hline \multicolumn{8}{|l|}{ Clinical outcome } \\
\hline ICU admission after pPCI & n (\%) & $30(6 \%)$ & $8(7 \%)$ & $5(4 \%)$ & $8(7 \%)$ & $9(7 \%)$ & NS \\
\hline Follow-up time & months & $28(23-34)$ & - & - & - & - & \\
\hline All-cause mortality & n (\%) & $78(14 \%)$ & $14(10 \%)$ & $23(16 \%)$ & $10(7 \%)$ & $31(22 \%)$ & $0.001^{\text {af }}$ \\
\hline CV mortality & n (\%) & $37(7 \%)$ & $3(2 \%)$ & $10(7 \%)$ & $6(4 \%)$ & $18(13 \%)$ & $0.002^{\mathrm{a}}$ \\
\hline Re-Ml & n (\%) & $46(8 \%)$ & $14(10 \%)$ & $10(7 \%)$ & $11(8 \%)$ & $11(8 \%)$ & NS \\
\hline Admission due to heart failure & n (\%) & $65(11 \%)$ & $9(6 \%)$ & $21(15 \%)$ & $12(8 \%)$ & $23(16 \%)$ & 0.023 \\
\hline
\end{tabular}

Data from all patients and patients stratified according to adrenaline quartiles are displayed. Data are presented as medians (IQR) or number (\%), with $P$-values shown for variables with $P<0.2$, and in bold for $P<0.05$. Adrenaline quartiles (Q1 to Q4) were compared by Kruskal-Wallis and Chi-square/Fischer exact tests, as appropriate, and by Bonferroni corrected Wilcoxon Rank Sum and Chi-square/Fisher exact post-hoc tests. Significant post-hoc test difference $(P<0.05)$ between: ${ }^{\mathrm{a}} \mathrm{Q} 1$ and $\mathrm{Q} 4,{ }^{\mathrm{b}} \mathrm{Q} 1$ and $\mathrm{Q} 3,{ }^{\mathrm{C}} \mathrm{Q} 1$ and $\mathrm{Q} 2,{ }^{\mathrm{d}} \mathrm{Q} 2$ and $\mathrm{Q} 4,{ }^{\mathrm{e}} \mathrm{Q} 2$ and $\mathrm{Q} 3,{ }^{\mathrm{f}} \mathrm{Q} 3$ and $\mathrm{Q} 4$.

$\mathrm{BMI}$, body mass index; BP, blood pressure; CRP, C-reactive protein; CV, cardiovascular; Cx, circumflex; eGFR, estimated glomerular filtration rate; LAD, left anterior descending; LM, left main; MI, myocardial infarction; n, number; NS, non-significant; PCI, primary coronary intervention; RCA, right coronary artery; STEMI, ST elevation myocardial infarction. 

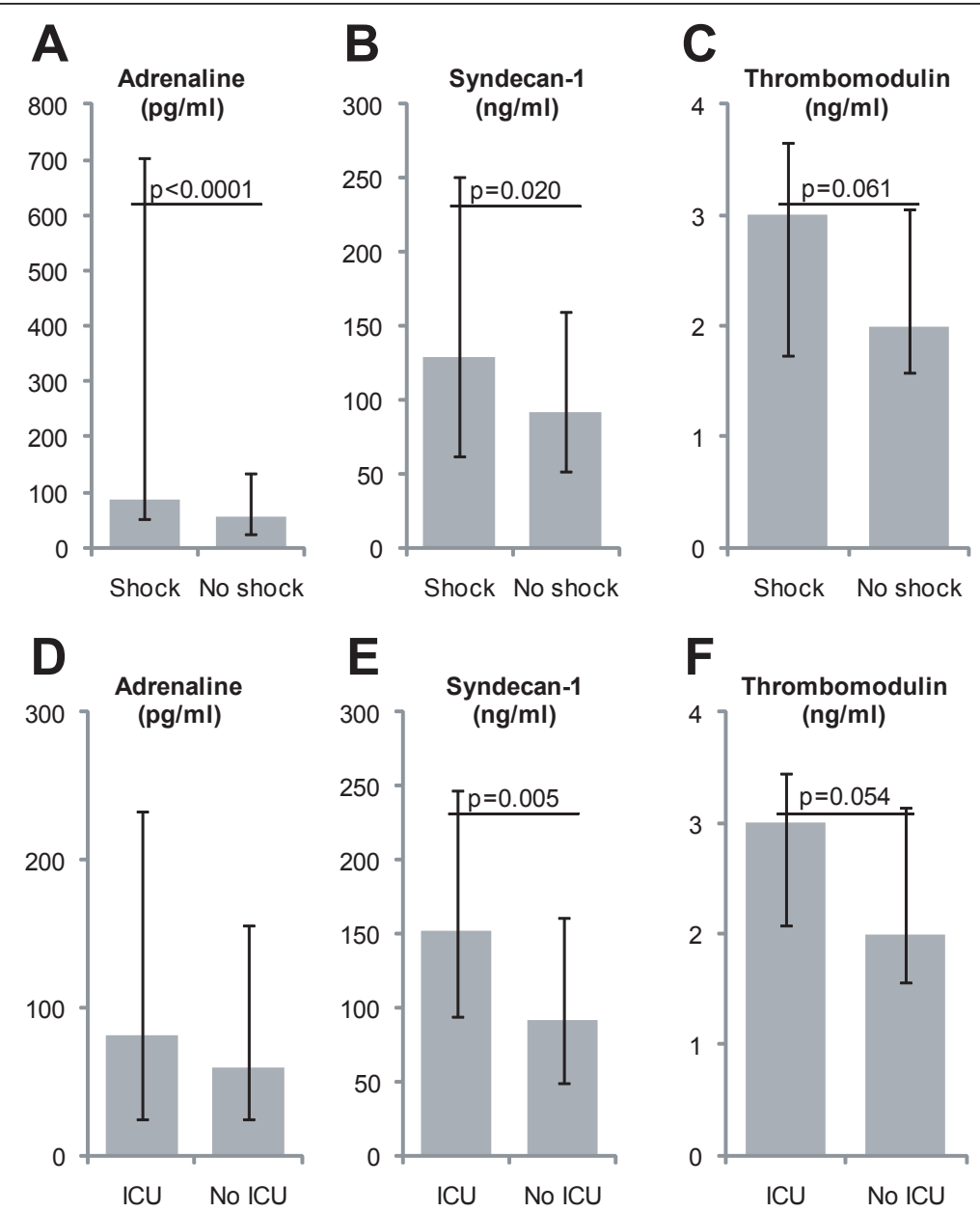

Figure 1 Plasma levels of adrenaline, syndecan-1 and thrombomodulin in STEMI-patients with or without shock prior to primary PCI ( $n=\mathbf{5 1}$ with shock, A-C) or ICU admission before discharge $(n=\mathbf{3 0}$ admitted to ICU, D-F). Medians with inter quartile ranges (IQR) are shown for adrenaline (pg/ml, A and D), syndecan-1 ( $\mathrm{ng} / \mathrm{ml}, \mathrm{B}$ and E) and thrombomodulin ( $\mathrm{ng} / \mathrm{ml}$ C and F). P-values for Wilcoxon Rank Sum tests are shown. PCl, primary coronary intervention; STEMI, ST elevation myocardial infarction.

in patients with shock or ICU admission (Figure 1C,F). eGFR was lower in patients with shock $(P<0.001)$ or ICU admission $(P<0.001)$ whereas noradrenaline, CRP and peak-TnI levels were comparable in patients with shock or ICU admission (data not shown).

Given that syndecan-1 was increased in both shocked and ICU patients, patients stratified according to syndecan-1 quartiles were investigated. With increasing syndecan-1 quartile ( $33 \mathrm{ng} / \mathrm{ml}$ (IQR 19 to 40), $69 \mathrm{ng} / \mathrm{ml}$ (IQR 59 to 79 ), $123 \mathrm{ng} / \mathrm{ml}$ (IQR 104 to 144 ) and $248 \mathrm{ng} / \mathrm{ml}$ (IQR 206 to 299) in Q1 to Q4, respectively), more patients had shock prior to PCI (Q1 to 4: 10\%, 5\%, 9\% and 19\%, $P=0.011)$ and eGFR decreased $(\mathrm{Q} 1$ to $4: 74 \mathrm{ml} / \mathrm{min}$, $76 \mathrm{ml} / \mathrm{min}, 72 \mathrm{ml} / \mathrm{min}$ and $71 \mathrm{ml} / \mathrm{min}, P=0.023$ ) whereas neutrophils (Q1 to $4: 8.6 \times 10^{9} / \mathrm{L}, 9.4 \times 10^{9} / \mathrm{L}, 9.4 \times 10^{9} / \mathrm{L}$ and $9.6 \times 10^{9} / \mathrm{L}, P=0.038$ ), platelet count (Q1 to $4: 271 \times$ $10^{9} / \mathrm{L}, 283 \times 10^{9} / \mathrm{L}, 272 \times 10^{9} / \mathrm{L}$ and $296 \times 10^{9} / \mathrm{L}$, $P=0.036$ ), CRP (Q1 to $4: 3 \mathrm{mg} / \mathrm{ml}, 3 \mathrm{mg} / \mathrm{ml}, 4 \mathrm{mg} / \mathrm{ml}$ and
$4 \mathrm{mg} / \mathrm{ml}, P=0.002)$ and sTM (Q1 to $4: 1.8 \mathrm{ng} / \mathrm{ml}, 2.1 \mathrm{ng} / \mathrm{ml}$, $2.3 \mathrm{ng} / \mathrm{ml}$ and $2.8 \mathrm{ng} / \mathrm{ml}, P<0.0001)$ increased. With increasing syndecan-1 quartile more patients went to the ICU post-PCI (Q1 to $4: 3 \%, 3 \%, 8 \%$ and $11 \%, P=0.027$ ) and more patients died (30-day all-cause mortality Q1 to 4: $3 \%, 3 \%, 5 \%$ and $12 \%, P<0.002$ and long-term all-cause mortality Q1 to $4: 9 \%, 10 \%, 12 \%$ and $23 \%, P<0.004$ ) or were admitted with HF (30-day HF Q1 to $4: 2 \%, 5 \%, 6 \%$ and $10 \%, P=0.008$ and long-term HF Q1 to $4: 6 \%, 11 \%, 13 \%$ and $15 \%, P=0.015)$ (data not shown).

\section{Correlations between catecholamines, endothelial} damage and markers of shock and infarction degree

Adrenaline and noradrenaline were highly positively correlated (rho $=0.43, P<0.001)$ and both adrenaline and noradrenaline correlated weakly positively with syndecan-1 (rho $=0.13, P=0.003$ and rho $=0.15, P<0.001$, respectively) and sTM (rho $=0.17, P<0.001$ and rho $=0.11$, 
$P=0.006$, respectively) when investigated in all patients. Since shock was associated with increased levels of adrenaline and syndecan-1, correlations between catecholamines and biomarkers of endothelial damage were investigated in patients stratified according to the presence or absence of shock prior to pPCI. In patients with shock, adrenaline and noradrenaline correlated even more strongly with syndecan-1 and sTM (Figure $2 \mathrm{~A}-\mathrm{D})$ whereas they did not correlate in patients without shock (data not shown).

In all patients, systolic blood pressure correlated negatively with adrenaline (rho $=-0.14, P<0.001$ ) and noradrenaline (rho $=-0.10, P=0.020$ ) but positively with eGFR (rho $=0.11, P=0.012$ ). eGFR correlated negatively with adrenaline (rho $=-0.11, P=0.006$ ), noradrenaline (rho $=-0.13, P=0.002)$ and sTM (rho $=-0.32, P<0.001)$. Peak TnI correlated positively with both noradrenaline (rho $=$ $0.09, P=0.026)$ and sTM (rho $=0.13, P=0.003)$.
Variables associated with biomarkers of endothelial damage

By univariate linear regression, higher adrenaline and noradrenaline, female gender, diabetes, shock prior to pPCI and lower eGFR were associated with higher syndecan-1 levels but in the multivariate model only noradrenaline, diabetes and shock prior to pPCI were independently associated with syndecan-1 (Table 2). Variables associated univariately with higher STM were higher adrenaline, noradrenaline, age and peak TnI, female gender, non-smoking status, diabetes, multivessel disease and lower BMI and eGFR whereas only adrenaline, diabetes, BMI and eGFR were independently associated with sTM (Table 3). Although syndecan-1 and sTM levels were strongly intercorrelated $(\mathrm{rho}=0.28, P$ $<0.0001)$, they were not included in the multivariate analyses since they both, by different means, reflect endothelial damage.

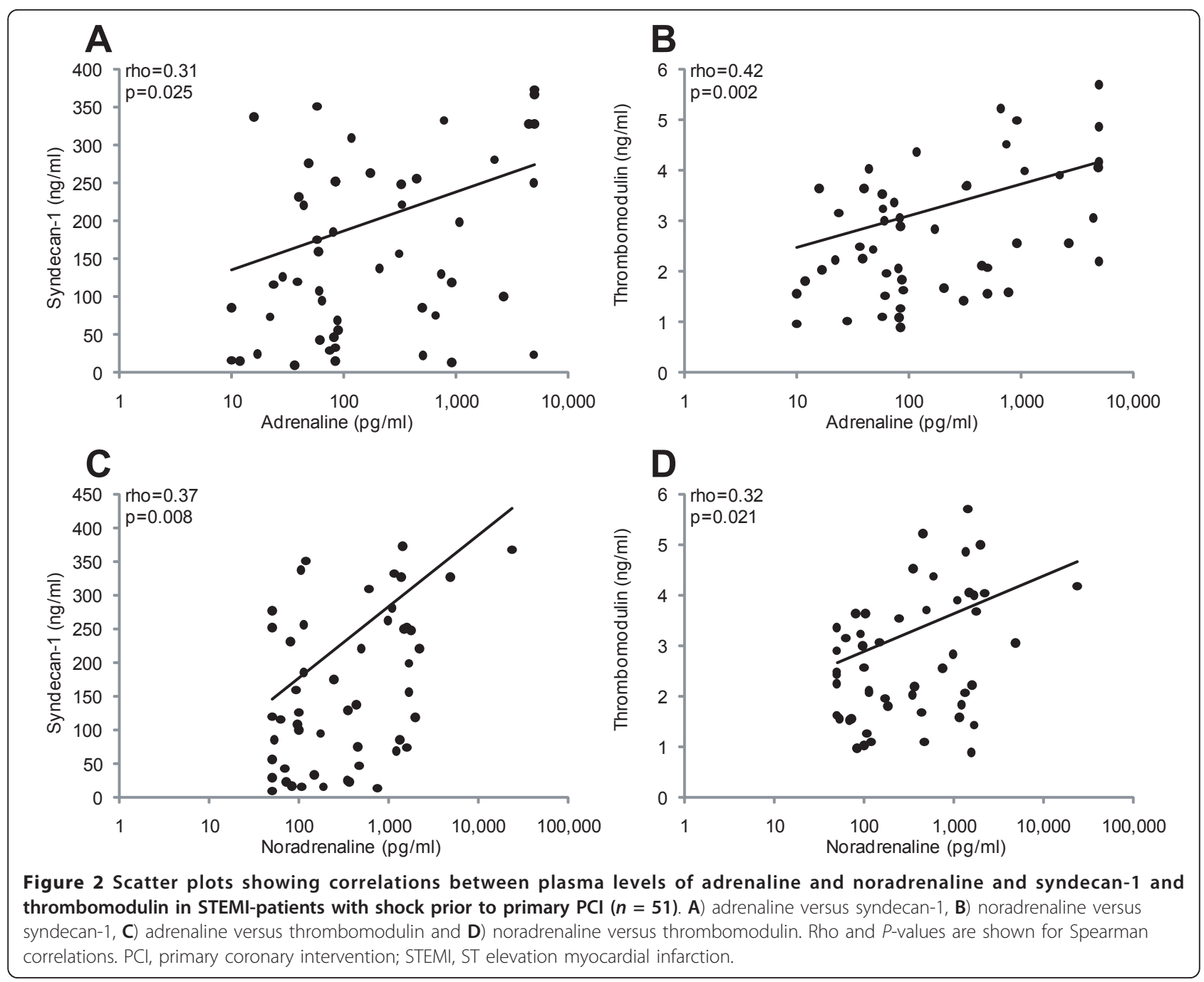


Table 2 Variables associated with plasma syndecan-1 by univariate and multivariate (backwards selection) linear regression analysis in 571 consecutive STEMI patients treated with primary PCI

\begin{tabular}{|c|c|c|c|c|c|c|c|}
\hline & & Univariate & & & Multivariate & & \\
\hline & & & & & $R^{2}=0.05$ & & \\
\hline & & $\beta(95 \% \mathrm{Cl})$ & $\mathrm{t}$ & $P$ & $\beta(95 \% \mathrm{Cl})$ & $\mathrm{t}$ & $P$ \\
\hline Adrenaline & $100 \mathrm{pg} / \mathrm{ml}$ & $1.64(0.58$ to 2.71$)$ & 3 & 0.003 & & & NS \\
\hline Noradrenaline & $100 \mathrm{pg} / \mathrm{ml}$ & 1.20 (0.57 to 1.84$)$ & 4 & $<0.001$ & 1.12 (0.46 to 1.78$)$ & 3 & 0.001 \\
\hline Male gender & yes & -24 (-41 to-8) & -3 & 0.004 & & & NS \\
\hline Diabetes & yes & 29 (4 to 54$)$ & 2 & 0.024 & 31 (3 to 58) & 2 & 0.032 \\
\hline eGFR & $\mathrm{ml} / \mathrm{min}$ & $-0.41(-0.72$ to -0.10$)$ & -3 & 0.009 & & & NS \\
\hline Peak Tnl & $\mu \mathrm{g} / \mathrm{L}$ & 0.04 (0 to 0.08 ) & 2 & 0.051 & & & NS \\
\hline Shock prior to $\mathrm{pPCl}$ & yes & 43 (17 to 69$)$ & 3 & 0.002 & 35 (8 to 61$)$ & 3 & 0.010 \\
\hline
\end{tabular}

Regression coefficients $(\beta)$ with $95 \%$ confidence intervals $(95 \% \mathrm{Cl})$, t-and $P$-values and $\mathrm{R}^{2}$ displayed for the multivariate models. $P$-values are shown in bold for variables with $P<0.05$. Predicted change in syndecan-1 (pg/ml) associated with one unit increase in adrenaline, noradrenaline, eGFR and peak Tnl, being male or having diabetes or shock prior to PPCI. eGFR, estimated glomerular filtration rate; PPCl, percutaneous primary coronary intervention; STEMI, ST elevation myocardial infarction; Tnl, troponin I.

Table 3 Variables associated with plasma thrombomodulin by univariate and multivariate (backwards selection) linear regression analysis in 571 consecutive STEMI patients treated with primary PCI

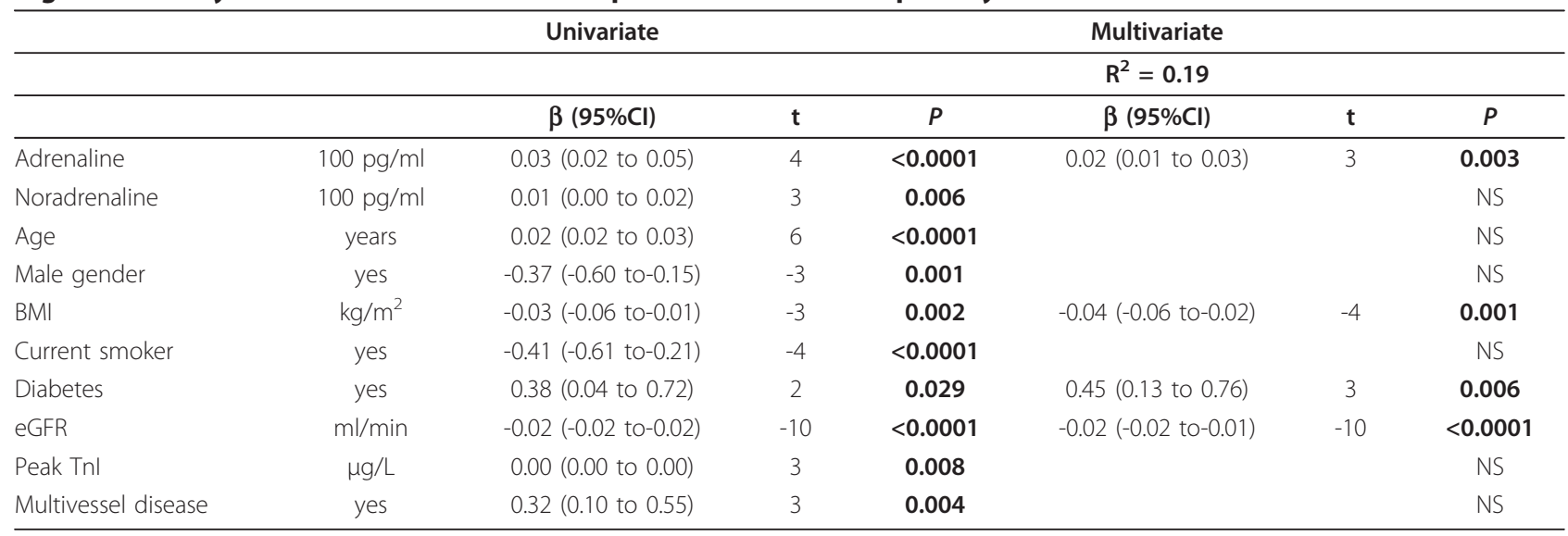

Regression coefficients $(\beta)$ with $95 \%$ confidence intervals $(95 \% \mathrm{Cl})$, t-and $P$-values and $\mathrm{R}^{2}$ displayed for the multivariate models. $P$-values are shown in bold for variables with $P<0.05$. Predicted change in thrombomodulin ( $\mathrm{pg} / \mathrm{ml}$ ) associated with one unit increase in adrenaline, noradrenaline, age, $\mathrm{BMI}$, eGFR and peak Tnl, being male, smoker or having diabetes or multivessel disease. BMI, body mass index; eGFR, estimated glomerular filtration rate; PCl, primary coronary

intervention; STEMI, ST elevation myocardial infarction; Tnl, troponin I.

\section{Catecholamines, endothelial damage and outcome}

During a median follow-up of 28 months (IQR 23 to 34), 78 (14\%) patients died (37 (7\%) from CV causes), 46 (8\%) had a re-MI and 65 (11\%) were admitted with HF (Table $1)$. With regard to the time-point of deaths, $42 \%(n=33)$ of all-cause fatal events occurred after 30 days.

Log-rank tests based on Kaplan-Meier curves for quartiles of adrenaline, syndecan-1 and sTM showed significant associations between high levels of each biomarker and increased 30-day and long-term all-cause and CV mortality (see Figure 3A-D for Kaplan-Meier plots of 30-day all-cause mortality). Kaplan-Meier curves for quartiles of adrenaline and noradrenaline also showed an association with 30-day and long-term admission for HF whereas syndecan-1 was only associated with 30-day HF and sTM only with long-term HF (data not shown).
When the associations between biomarkers and mortality were investigated by univariate Cox analyses, each increase in adrenaline, syndecan-1 or sTM quartiles was associated with increased risk of 30-day (Table 4) and long-term (all $P<0.05$, data not shown) all-cause and CV mortality and HF. After adjusting for conventional risk factors, adrenaline remained an independent predictor of 30-day all-cause mortality and HF (Table 4) and of long-term CV mortality $(P=0.014)$ and syndecan-1 remained an independent predictor of long-term all-cause mortality $(P=0.034)$. Noradrenaline was a univariate predictor of long-term CV mortality $(P=0.031)$ and longterm HF $(P=0.039)$. None of the investigated biomarkers could predict re-MI (Table 4 and data not shown).

Compared to the independent predictive value of conventional risk factors for outcome in MI patients in the present study (age, systolic BP, eGFR, peak TnI, CRP, 


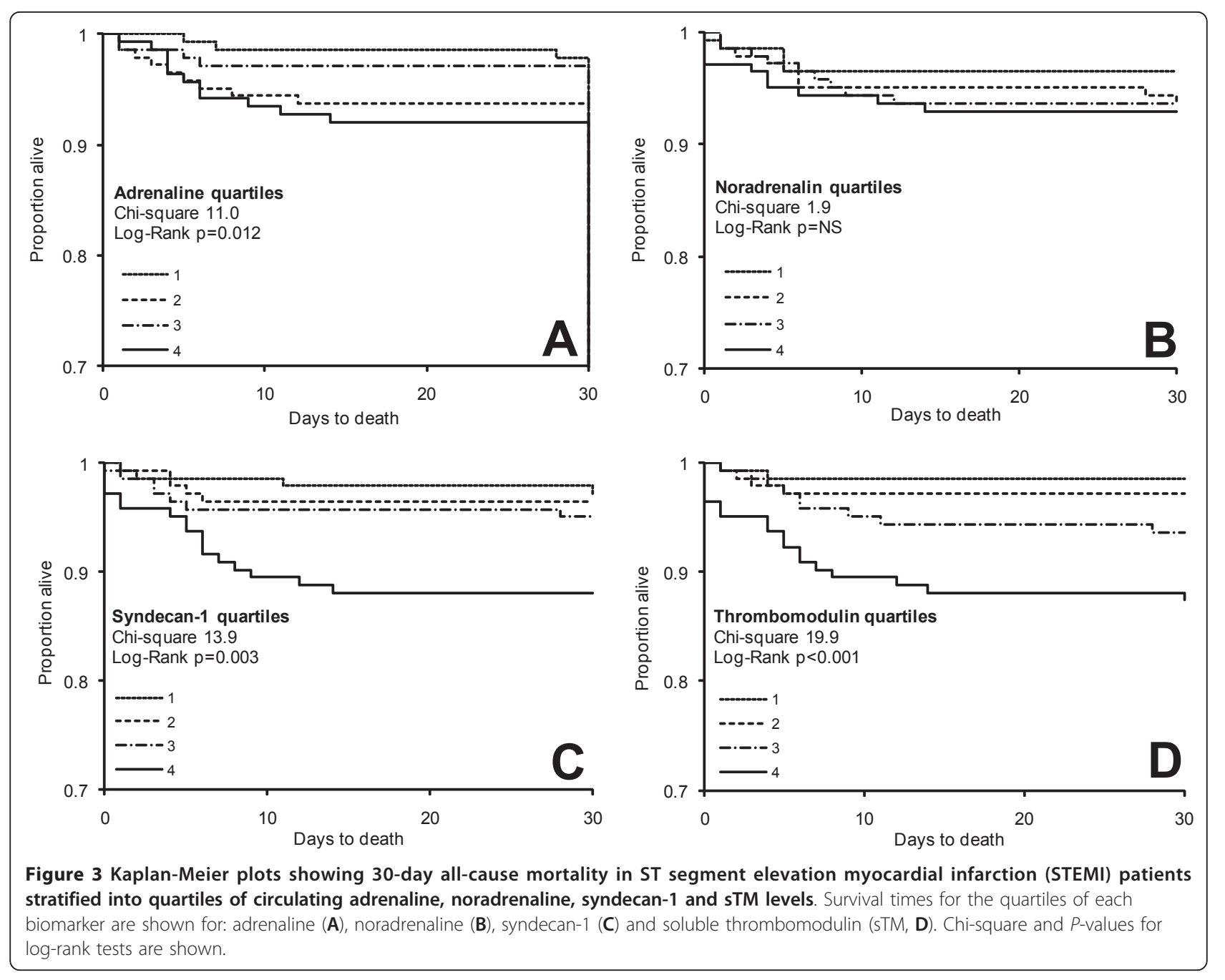

Table 4 Cox Proportional Hazards models predicting 30-day all-cause and cardiovascular (CV) mortality and heart failure in 571 consecutive STEMI patients treated with primary PCI.

\begin{tabular}{|c|c|c|c|c|c|c|c|c|c|c|}
\hline & & & Adrenaline & & Noradrenaline & & Syndecan-1 & & Thrombomoduli & \\
\hline & & & HR $(95 \% \mathrm{Cl})$ & $P$ & HR $(95 \% \mathrm{Cl})$ & $P$ & HR $(95 \% \mathrm{Cl})$ & $P$ & HR $(95 \% \mathrm{Cl})$ & $P$ \\
\hline \multirow[t]{2}{*}{ All-cause mortality } & 30-day & uni & $1.42(1.03-1.96)$ & 0.032 & & NS & $1.74(1.23-2.45)$ & 0.002 & $2.13(1.46-3.11)$ & $<0.0001$ \\
\hline & & multi ${ }^{a}$ & $1.39(1.01-1.92)$ & 0.046 & & NS & $1.29(0.90-1.85)$ & 0.166 & & NS \\
\hline \multirow[t]{2}{*}{ CV mortality } & 30-day & uni & $1.45(1.02-2.05)$ & 0.038 & $1.27(0.91-1.78)$ & 0.167 & $1.59(1.11-2.28)$ & 0.012 & $2.39(1.54-3.68)$ & $<0.0001$ \\
\hline & & multib & $1.39(0.98-1.96)$ & 0.066 & & NS & & NS & $1.49(0.93-2.38)$ & 0.098 \\
\hline \multirow[t]{2}{*}{ Re-Ml } & 30-day & uni & & NS & & NS & $0.71(0.43-1.17)$ & 0.176 & & NS \\
\hline & & multic $^{c}$ & & NS & & NS & & NS & & NS \\
\hline \multirow[t]{2}{*}{ Heart failure } & 30-day & uni & $1.40(1.02-1.92)$ & 0.041 & $1.31(0.96-1.80)$ & 0.091 & $1.66(1.19-2.32)$ & 0.003 & $1.53(1.10-2.12)$ & 0.011 \\
\hline & & multi $^{d}$ & $1.65(1.17-2.34)$ & 0.005 & $1.29(0.93-1.79)$ & 0.135 & $1.38(0.98-1.94)$ & 0.069 & & NS \\
\hline
\end{tabular}

Hazards ratios (HR) with $95 \%$ confidence intervals $(\mathrm{HR}(95 \% \mathrm{CI})$ ) and $P$-values associated with increased quartiles of adrenaline, noradrenaline, syndecan-1 or thrombomodulin are shown for univariate and multivariate analyses, with $P$-values in bold for variables with $p<0.05$. The applied multivariate Cox proportional hazards models (MV) included variables significant for 30-day events in the univariate analyses: ${ }^{\text {a }}$ (30-day all-cause mortality, $\left.n=33\right)$ age $(<0.001)$, systolic blood pressure $(<0.0001)$, eGFR $(<0.0001)$, peak Tnl $(<0.001)$, multivessel disease $(<0.01)$; ${ }^{b}(30$-day CV mortality, $n=28)$ systolic blood pressure $(<0.001)$, eGFR $(<0.0001)$, peak Tnl $(<0.0001)$, multivessel disease $(<0.01)$; ${ }^{c}(30$-day re-MI, $n=14)$ leukocyte count $(<0.0001)$; ${ }^{d}(30$-day heart failure, $n=33)$ age $(<0.0001), \mathrm{BMI}(<0.01)$, CV, cardiovascular; eGFR (<0.0001), CRP (<0.0001), peak Tnl $(<0.0001)$. BMI, body mass index; CRP, C-reaction protein; eGFR, estimated glomerular filtration rate; PCl, primary coronary intervention; Re-MI, Re myocardial infarction; STEMI, ST elevation myocardial infarction, TN1, troponin I. 
multivessel disease, $P$-values displayed in Table 4 footer), the predictive value of the investigated biomarkers was weak.

\section{Discussion}

Here, we report that circulating adrenaline and noradrenaline levels in STEMI-patients treated with pPCI correlated with syndecan-1 and sTM, biomarkers of glycocalyx and endothelial cell damage, respectively, with the strongest correlations, and highest adrenaline and syndecan-1 levels, in patients with shock. Furthermore, circulating levels of adrenaline and syndecan-1 were associated independently with short-and long-term mortality and HF and with long-term mortality, respectively. These findings demonstrate that acute MI appears to cause significant endothelial cell and glycocalyx injury and a parallel increase in circulating catecholamines. They also support the notion that a dose-dependent association between disease severity, sympathoadrenal activation and endothelial damage exists in critically ill non-trauma patients in accordance with that previously observed in trauma patients $[7,9]$.

The vascular endothelium comprises a single layer of cells that lines every blood vessel in the body, covers a total surface area of 4 to $7,000 \mathrm{~m}^{2}$, totaling a weight of 1 kilogram [32]. On top of the endothelium lies the glycocalyx, an approximately $1 \mu \mathrm{m}$ thick carbohydrate-rich structure with antiadhesive and anticoagulant properties that protects the endothelium and maintains vascular barrier function [22,23]. The endothelium is critically involved in the pathology of multiple diseases, in which there exist a well established association between endothelial dysfunction and/or damage and poor outcome $[8,9,20-24]$. In the present study, we investigated associations between potential drivers of sympathoadrenal activation, endothelial damage and outcome in patients with increased sympathoadrenal activation in the absence of massive tissue injury. Our findings confirmed, in a different cohort of patients, the previous finding in trauma patients of associations between shock, catecholamines, biomarkers of glycocalyx and endothelial cell damage and outcome [7-9]. Although the median circulating levels of adrenaline and noradrenaline in trauma patients (290 pg/ml (IQR 190 to 720 ) and $750 \mathrm{pg} / \mathrm{ml}$ (IQR 450 to 1,380), respectively) [7,9] are four-to five-fold higher than the median levels observed in STEMI-patients in this study (Table 1), STEMIpatients in the highest adrenaline quartile, representing the most critically ill and shocked patients, had catecholamine levels comparable to those observed in trauma patients [7,9]. Although we found correlations between catecholamines and biomarkers of endothelial damage in the whole patient cohort, these were weak and strongest in patients with shock, in accordance with the notion that a dose-response relationship may exist between catecholamine levels and infliction of endothelial injury [4-6].

Glycocalyx damage is associated with pathophysiologic sequels, such as capillary leakage and edema formation, accelerated inflammation, platelet activation and hypercoagulability and loss of vascular responsiveness [22]. It is becoming increasingly evident that glycocalyx damage represents the earliest stage of endothelial perturbation $[22,23]$. In STEMI-patients, several factors may contribute to glycocalyx damage, that is, ischemia-reperfusion injury, shock, inflammation (TNF- $\alpha$ ), hyperglycemia, atrial natriuretic peptide and oxidized low density lipoprotein (LDL). Thus, in accordance with previous studies reporting that shock [21,25-27] and hyperglycemia/ diabetes $[7,23,33]$ are associated with glycocalyx damage, shock and diabetes were independently associated with circulating syndecan-1 in the present study (Table 2). With increasing syndecan-1 quartile, the neutrophil and platelet count and CRP increased whereas eGFR decreased. The finding that patients with shock displayed the strongest correlations between catecholamines and endothelial damage supports the notion that a threshold level exists above which catecholamines exert deleterious effects on the endothelial glycocalyx and cells.

We also found that syndecan-1 was associated independently with mortality and, to the best of our knowledge, this association has not been reported previously. Given the emerging evidence for devastating effects of glycocalyx damage in acute [9,22,27] and chronic [23] illness, including cardiovascular disease [21-23], this finding is notable.

In accordance with previous studies, higher age [34], male gender [34,35], non-smoking [34,35], diabetes [34] and impaired kidney function [36] were associated with higher circulating sTM, in addition to higher adrenaline levels, lower BMI, myocardial cell damage (TnI) and multivessel disease. Circulating adrenaline, BMI, diabetes and eGFR were independently associated with sTM (Table 3), indicating that both life style factors and acute critical illness may contribute to endothelial damage.

In the present study, more patients in the highest adrenaline quartile died or developed HF. Adrenaline was independently associated with mortality and HF which is in accordance with previous findings reporting (varying degrees of) association between early increases in circulating adrenaline levels and mortality in MIpatients $[11,37,38]$. From a pathophysiologic point of view, MI-induced sympathoadrenal activation may later aggravate chronic atherosclerosis [39]. In some studies 
the early adrenaline surge in MI-patients has been correlated with the extent of myocardial damage/infarct size $[11,40]$ and left ventricular ejection fraction (LVFE) [38]. Although we could not replicate these associations, we found a borderline significant association between adrenaline levels and complex lesions (Table 1). It should be emphasized that the above findings do not prove any cause-effect relationship between early adrenaline levels, endothelial damage and poor outcome post-MI since it is expected that the most critically ill patients have the highest sympathoadrenal response and the poorest outcome. Also, it is possible that differences in the sympathoadrenal response attributed to gene polymorphisms in adrenergic receptors may in part explain our findings [41]. However, it is notable that the most critically ill and shocked MI patients presented with evidence of enhanced endothelial damage that correlated more strongly with catecholamines than in less sick patients. Whatever drivers among shock, ischemiareperfusion injury, catecholamines, hyperglycemia, and so on that inflict the greatest endothelial damage, the magnitude of increase in endothelial derived biomarkers may be interpreted as a surrogate for concurrent organ damage and this may, in part, explain the negative predictive value associated with these biomarkers.

With regard to noradrenaline, this was a univariate predictor of long-term HF and CV mortality in this study. Although noradrenaline is a strong predictor of poor outcome in patients with asymptomatic left ventricular dysfunction [42] and chronic HF [3], the weak predictive value for outcome compared with adrenaline may both reflect that we investigated an early noradrenaline response, which may peak after PCI [43], and that noradrenaline release is much more heterogeneous compared to adrenaline release; for example, noradrenaline is released directly from the infarcted myocardium [12].

The results presented here are subject to the limitations inherent to observational studies and, therefore, do not allow independent evaluation of the cause and effect relationship between catecholamine levels, endothelial damage and outcome, so evidence of potential cause and effect relationships should come from adequately designed prospective trial(s). We found a relatively low prevalence of diabetes, previous MI and known HF prior to STEMI. Thus, care should be taken if the results are to be extrapolated to populations with very different distributions of potential risk factors and logistic facilities. Also, our geographical and organizational conditions may not necessarily apply to other countries and regions, and our findings should not be extrapolated to settings without high volume PCI centers. Finally, we did not have data on predictive ICU scores (Sequential Organ Failure Assessment, Acute Physiology and Chronic Health Evaluation, and so on) and we did not have data on previous $\beta$-adrenergic receptor blockers before admission.

\section{Conclusions}

The present study found an association between shock, circulating catecholamine levels, biomarkers indicative of endothelial damage, and outcome in STEMI-patients treated with pPCI, in accordance with previous findings in trauma patients. Patients in shock presented with the highest levels of adrenaline and syndecan-1, and the correlations between catecholamines and endothelialderived biomarkers were particularly strong in patients in shock. These findings demonstrate that acute MI appears to cause significant endothelial cell and glycocalyx injury and a parallel increase in circulating catecholamines. The predictive value of the endothelial-derived biomarkers for outcome in STEMI patients may indicate that these, in part, reflect the extent of acute (ischemic/ catecholamine induced) organ damage, thereby providing a prognostic value.

\section{Key messages}

- Sympathoadrenal activation is a hallmark of acute critical illness but this fight-or-flight response may become maladaptive and contribute to organ damage; in high concentrations catecholamines directly damage the vascular endothelium.

- In STEMI-patients circulating levels of adrenaline and noradrenaline correlated with levels of thrombomodulin and syndecan-1, biomarkers of endothelial cell and glycocalyx damage, with the strongest correlations in patients in shock.

- STEMI-patients with shock prior to PCI had the highest circulating adrenaline and syndecan-1 levels and patients admitted to ICU after PCI had the highest syndecan-1 levels.

- Circulating levels of adrenaline and syndecan-1 were associated independently with mortality and heart failure.

- Acute MI appears to cause significant endothelial cell and glycocalyx injury and a parallel increase in circulating catecholamines; these findings support the existence of a dose-dependent association between disease severity, sympathoadrenal activation and endothelial damage in critically ill non-trauma patients in accordance with that previously observed in trauma patients.

\section{Abbreviations}

CV: cardiovascular; CRP: C-reactive protein; EDTA: ethylenediaminetetraacetic acid; eGFR: estimated glomerular filtration rate; ELISA: enzyme-linked immunosorbent assay; HF: heart failure; LDL: low density lipoprotein; LLD: lower limit of detection; MI: myocardial infarction; PPCl: primary percutaneous coronary intervention; SICAM-1: soluble intercellular adhesion 
molecule-1; sTM: soluble thrombomodulin; sVCAM-1: soluble vascular cell adhesion molecule-1; STEMI: ST elevation Ml; Tnl: troponin I.

\section{Authors' contributions}

SRO participated in the conception of the study and in data acquisition, performed the statistical analysis and data interpretation and drafted the manuscript. SHP, JSJ and RM participated in the conception and design of the study and acquisition of data and helped to draft the manuscript. PIJ participated in the conception of the study, acquisition and interpretation of data and helped to draft the manuscript. All authors read and approved the final manuscript.

\section{Competing interests}

The authors declare that they have no competing interests.

\section{Acknowledgements}

Laboratory technicians Karen Dyeremose and Marie Helena Andersson are thanked for their skilled technical assistance.

\section{Author details}

'Section for Transfusion Medicine at Capital Region Blood Bank, Rigshospitalet, Blegdamsvej 9, Copenhagen, DK-2100, Denmark. ²Department of Cardiology P, Gentofte Hospital, Niels Andersens Vej 65, Hellerup, DK2900, Denmark. ${ }^{3}$ Clinical Institute of Surgery and Internal Medicine, Faculty of Health Science at University of Copenhagen, Blegdamsvej 3B, Copenhagen, DK-2200, Denmark. ${ }^{4}$ Department of Cardiology, Rigshospitalet, Blegdamsvej 9, Copenhagen, DK-2100, Denmark. ${ }^{5}$ Department of Surgery, Center for Translational Injury Research (CeTIR) at University of Texas Medical School at Houston, 6410 Fannin Street, Houston, TX 77030, USA.

Received: 14 November 2012 Revised: 28 January 2013 Accepted: 19 February 2013 Published: 22 February 2013

\section{References}

1. Cryer PE: Physiology and pathophysiology of the human sympathoadrenal neuroendocrine system. N Engl J Med 1980, 303:436-444.

2. Dunser MW, Hasibeder WR: Sympathetic overstimulation during critical illness: adverse effects of adrenergic stress. J Intensive Care Med 2009, 24:293-316.

3. Triposkiadis F, Karayannis G, Giamouzis G, Skoularigis J, Louridas G, Butler J: The sympathetic nervous system in heart failure physiology, pathophysiology, and clinical implications. J Am Coll Cardiol 2009, 54:1747-1762

4. Johansson PI, Ostrowski SR: Acute coagulopathy of trauma: balancing progressive catecholamine induced endothelial activation and damage by fluid phase anticoagulation. Med Hypotheses 2010, 75:564-567.

5. Makhmudov RM, Mamedov Y, Dolgov W, Repin VS: Catecholaminemediated injury to endothelium in rabbit perfused aorta: a quantitative analysis by scanning electron microscopy. Cor Vasa 1985, 27:456-463.

6. Kristova V, Kriska M, Canova R, Hejdova E, Kobzova D, Dobrocky P: Endothelial changes following repeated effect of vasoconstrictive substances in vitro. Acta Physiol Hung 1993, 81:363-370.

7. Johansson PI, Stensballe J, Rasmussen LS, Ostrowski SR: High circulating adrenaline levels at admission predict increased mortality after trauma. $J$ Trauma Acute Care Surg 2012, 72:428-436.

8. Ostrowski SR, Sørensen AM, Windeløv NA, Perner A, Welling KL, Wanscher M, Larsen CF, Johansson PI: High levels of soluble VEGF receptor 1 early after trauma are associated with shock, sympathoadrenal activation, glycocalyx degradation and inflammation. Scand J Trauma Resusc Emerg Med 2012, 20:27.

9. Johansson PI, Stensballe J, Rasmussen LS, Ostrowski SR: A high admission syndecan-1 level, a marker of endothelial glycocalyx degradation, is associated with inflammation, protein $\mathrm{C}$ depletion, fibrinolysis, and increased mortality in trauma patients. Ann Surg 2011, 254:194-200.

10. Rehm M, Bruegger D, Christ F, Conzen P, Thiel M, Jacob M, Chappell D, Stoeckelhuber M, Welsch U, Reichart B, Peter K, Becker BF: Shedding of the endothelial glycocalyx in patients undergoing major vascular surgery with global and regional ischemia. Circulation 2007, 116:1896-1906.

11. Karlsberg RP, Cryer PE, Roberts R: Serial plasma catecholamine response early in the course of clinical acute myocardial infarction: relationship to infarct extent and mortality. Am Heart J 1981, 102:24-29.
12. Richardt G, Munch G, Neumann FJ, Rauch B, Kurz T: Systemic and cardiac catecholamines during elective PTCA and during immediate PTCA for acute myocardial infarction. Basic Res Cardiol 1997, 92:52-60.

13. von Kanel R, Dimsdale JE: Effects of sympathetic activation by adrenergic infusions on hemostasis in vivo. Eur J Haematol 2000, 65:357-369.

14. Hawkey CM, Britton BJ, Wood WG, Peele M, Irving MH: Changes in blood catecholamine levels and blood coagulation and fibrinolytic activity in response to graded exercise in man. Br J Haematol 1975, 29:377-384.

15. Sefrin P: Catecholamines in the serum of multiple trauma patientsmediators of ARDS? Prog Clin Biol Res 1987, 236:477-486.

16. van der PT, Levi M, Dentener M, Jansen PM, Coyle SM, Braxton CC, Buurman WA, Hack CE, ten Cate JW, Lowry SF: Epinephrine exerts anticoagulant effects during human endotoxemia. J Exp Med 1997, 185:1143-1148

17. Johansson Pl, Stissing T, Bochsen L, Ostrowski SR: Thrombelastography and tromboelastometry in assessing coagulopathy in trauma. Scand J Trauma Resusc Emerg Med 2009, 17:45.

18. Ostrowski SR, Sorensen AM, Larsen CF, Johansson PI: Thrombelastography and biomarker profiles in acute coagulopathy of trauma: A prospective study. Scand J Trauma Resusc Emerg Med 2011, 19:64.

19. Schochl H, Cadamuro J, Seidl S, Franz A, Solomon C, Schlimp CJ, Ziegler B: Hyperfibrinolysis is common in out-of-hospital cardiac arrest: Results from a prospective observational thromboelastometry study. Resuscitation 2012, doi: 10.1016/j.resuscitation.2012.08.318.

20. Gando S, Nanzaki S, Morimoto Y, Kobayashi S, Kemmotsu O: Out-ofhospital cardiac arrest increases soluble vascular endothelial adhesion molecules and neutrophil elastase associated with endothelial injury. Intensive Care Med 2000, 26:38-44.

21. Grundmann S, Fink K, Rabadzhieva L, Bourgeois N, Schwab T, Moser M, Bode C, Busch HJ: Perturbation of the endothelial glycocalyx in post cardiac arrest syndrome. Resuscitation 2012, 83:715-720.

22. Becker BF, Chappell D, Bruegger D, Annecke T, Jacob M: Therapeutic strategies targeting the endothelial glycocalyx: acute deficits, but great potential. Cardiovasc Res 2010, 87:300-310.

23. Salmon AH, Satchell SC: Endothelial glycocalyx dysfunction in disease: albuminuria and altered microvascular permeability. J Pathol 2012, 226:562-574

24. Aird WC: The role of the endothelium in severe sepsis and multiple organ dysfunction syndrome. Blood 2003, 101:3765-3777.

25. Haywood-Watson R, Pati S, Kozar R, Faz J, Holcomb JB, Gonzalez E: Human micro-vascular barrier disruption after hemorrhagic shock. J Surg Res 2010, 158:313

26. Kozar RA, Peng Z, Zhang R, Holcomb JB, Pati S, Park P, Ko TC, Paredes A: Plasma restoration of endothelial glycocalyx in a rodent model of hemorrhagic shock. Anesth Analg 2011, 112:1289-1295.

27. Haywood-Watson RJ, Holcomb JB, Gonzalez EA, Peng Z, Pati S, Park PW, Wang W, Zaske AM, Menge T, Kozar RA: Modulation of syndecan-1 shedding after hemorrhagic shock and resuscitation. PLOS ONE 2011, 6: e23530.

28. Ishii H, Uchiyama H, Kazama M: Soluble thrombomodulin antigen in conditioned medium is increased by damage of endothelial cells. Thromb Haemost 1991, 65:618-623.

29. Blann A, Seigneur M: Soluble markers of endothelial cell function. Clin Hemorheol Microcirc 1997, 17:3-11.

30. Boffa MC: Considering cellular thrombomodulin distribution and its modulating factors can facilitate the use of plasma thrombomodulin as a reliable endothelial marker? Haemostasis 1996, 26(Suppl 4):233-243.

31. Lindberg S, Pedersen SH, Mogelvang R, Bjerre M, Frystyk J, Flyvbjerg A, Galatius S, Jensen JS: Usefulness of adiponectin as a predictor of all cause mortality in patients with ST-segment elevation myocardial infarction treated with primary percutaneous coronary intervention. Am J Cardiol 2012, 109:492-496.

32. Aird WC: Endothelium as an organ system. Crit Care Med 2004, 32: S271-S279.

33. Nieuwdorp M, van Haeften TW, Gouverneur MC, Mooij HL, van Lieshout MH, Levi M, Meijers JC, Holleman F, Hoekstra JB, Vink H, Kastelein JJ, Stroes ES: Loss of endothelial glycocalyx during acute hyperglycemia coincides with endothelial dysfunction and coagulation activation in vivo. Diabetes 2006, 55:480-486.

34. Salomaa V, Matei C, Aleksic N, Sansores-Garcia L, Folsom AR, Juneja $H_{\text {, }}$ Chambless LE, Wu KK: Soluble thrombomodulin as a predictor of incident coronary heart disease and symptomless carotid artery atherosclerosis 
in the Atherosclerosis Risk in Communities (ARIC) Study: a case-cohort study. Lancet 1999, 353:1729-1734.

35. Blann AD, McCollum CN, Lip GY: Relationship between plasma markers of endothelial cell integrity and the Framingham cardiovascular disease risk-factor scores in apparently healthy individuals. Blood Coagul Fibrinolysis 2002, 13:513-518.

36. Seigneur M, Dufourca P, Conri C, Constans J, Mercie P, Pruvost A, Amiral J Midy D, Baste JC, Boisseau MR: Levels of plasma thrombomodulin are increased in atheromatous arterial disease. Thromb Res 1993, 71:423-431.

37. Omland T, Aarsland T, Aakvaag A, Lie RT, Dickstein K: Prognostic value of plasma atrial natriuretic factor, norepinephrine and epinephrine in acute myocardial infarction. Am J Cardiol 1993, 72:255-259.

38. Katayama T, Nakashima H, Furudono $S$, Honda $Y$, Suzuki $S$, Yano K:

Evaluation of neurohumoral activation (adrenomedullin, BNP, catecholamines, etc.) in patients with acute myocardial infarction. Intern Med 2004, 43:1015-1022.

39. Dutta P, Courties G, Wei Y, Leuschner F, Gorbatov R, Robbins CS, Iwamoto Y, Thompson B, Carlson AL, Heidt T, Majmudar MD, Lasitschka F, Etzrodt M, Waterman P, Waring MT, Chicoine AT, van der Laan AM, Niessen HWM, Piek JJ, Rubin BB, Butany J, Stone JR, Katus HA, Murphy SA, Morrow DA, Sabatine MS, Vinegoni C, Moskowitz MA, Pittet MJ, Libby P, et al: Myocardial infarction accelerates atherosclerosis. Nature 2012, 487:325-329.

40. Oswald GA, Smith CC, Betteridge DJ, Yudkin JS: Determinants and importance of stress hyperglycaemia in non-diabetic patients with myocardial infarction. Br Med J (Clin Res Ed) 1986, 293:917-922.

41. Leineweber K, Heusch G: Beta 1-and beta 2-adrenoceptor polymorphisms and cardiovascular diseases. Br J Pharmacol 2009, 158:61-69.

42. Benedict CR, Shelton B, Johnstone DE, Francis G, Greenberg B, Konstam M, Probstfield JL, Yusuf S: Prognostic significance of plasma norepinephrine in patients with asymptomatic left ventricular dysfunction. SOLVD Investigators. Circulation 1996, 94:690-697.

43. Hartmann F, Kurowski V, Maghsoudi A, Kurz T, Schwarz M, Bonnemeier H, Tolg R, Jain D, Wiegand U, Katus H, Richardt G: Plasma catecholamines and $\mathrm{N}$-terminal proBNP in patients with acute myocardial infarction undergoing primary angioplasty. Relation to left ventricular function and clinical outcome. Z Kardiol 2003, 92:73-81.

doi:10.1186/cc12532

Cite this article as: Ostrowski et al:: Acute myocardial infarction is associated with endothelial glycocalyx and cell damage and a parallel increase in circulating catecholamines. Critical Care 2013 17:R32.

\section{Submit your next manuscript to BioMed Central and take full advantage of:}

- Convenient online submission

- Thorough peer review

- No space constraints or color figure charges

- Immediate publication on acceptance

- Inclusion in PubMed, CAS, Scopus and Google Scholar

- Research which is freely available for redistribution

Submit your manuscript at www.biomedcentral.com/submit
Biomed Central 